\title{
EVALUACIÓN DE UNA VACUNA CONTRACorynebacterium pseudotuberculosis EN RATONES ALBINOS
}

Giuliana Medrano G. ${ }^{1}$, Armando Hung Ch. ${ }^{2,3}$, Arnaldo Alvarado S. ${ }^{2}$ y Olga Li E. ${ }^{2}$

\section{A BSTRACT}

The granulomatous lymphadenitis is an economically important infectious disease in alpacas. This disease is caused by Corynebacterium pseudotuberculosis, which is a gram positive bacterium that has an exotoxin (Phospholipase D) as its main virulence factor. The objective of this study was to test the efficacy of a vaccine in a group of mice (20 vaccinated and 20 control). The vaccine was prepared with protein extracts from $C$. pseudotuberculosis isolated from an alpaca, containing the exotoxin, and used for the immunization of mice which received $16 \mathrm{~g}$ of protein extract. This confered protection after challenging intraperitoneally with $10^{4} \mathrm{UFC}$ of $C$. pseudotuberculosis. The vaccine ameliorated the toxic effects of $C$. pseudotuberculosis, which was evidenced by the decrease in number and size of abscesses in the vaccinated group (40\% affected), in contrast with the severe and systemic damages found in the control animals (95\% affected). Furthermore, a PCR methodology was set up in order to detect C. pseudotuberculosis in the experimental animals which showed abscesses, producing a band of $815 \mathrm{bp}$, indicating that $C$. pseudotuberculosis was the pathogen agent involved in the infections.

Key words: Corynebacterium pseudotuberculosis, exotoxin, mice, alpaca, PCR

\section{RESUMIEN}

La linfadenitis granulomatosa es una enfermedad de significancia económica en alpacas, la cual es causada por Corynebacterium pseudotuberculosis, una bacteria gram positiva cuyo principal factor de virulencia es una exotoxina (fosfolipasa D). El objetivo del presente trabajo fue probar la eficacia de una vacuna elaborada a partir de precipitado proteico de $C$. pseudotuberculosis conteniendo la exotoxina, en un grupo de 20 ratones (grupo vacunado), quienes recibieron el inóculo con C.pseudotuberculosis, frente a otro grupo de 20 ratones (grupo control), quienes recibieron placebo y el inóculo. La inmunización del grupo vacunado con $16 \mathrm{~g}$ del precipitado proteico de C. pseudotuberculosis indujo protección después de la inoculación intraperitoneal con $10^{4}$ UFC de $C$. pseudotuberculosis. La vacuna disminuyó los efectos tóxicos del C. pseudotuberculosis, lo cual se observó con la disminución del número y tamaño de abscesos de los animales del grupo vacunado ( $40 \%$ afectado) comparado con las lesiones severas y generalizadas encontradas en los animales del grupo control (95\% afectado). Como parte de la metodología se desarrolló la técnica de PCR para la detección de C.pseudotuberculosis en los animales que presentaban abscesos, encontrándose una banda de DNA de 815 bp, demostrándose así al C. pseudotuberculosis como agente causal de la infección.

Palabras clave: Corynebacterium pseudotuberculosis, exotoxina, ratones, alpacas, PCR

\footnotetext{
${ }^{1}$ Práctica privada

${ }^{2}$ Laboratorio de Patología Clínica, FMV-UNMSM

${ }^{3}$ Dirección actual: Facultad de Veterinaria y Zootecnia, Universidad Peruana Cayetano Heredia
} 
La linfadenitis granulomatosa es una enfermedad infectocontagiosa de las alpacas, de curso generalmente crónico, enzoótica, causada por el Corynebacterium pseudotuberculosis y caracterizada por la formación de abscesos en nódulos linfáticos y órganos internos. En estudios microbiológicos efectuados en el Perú se ha aislado el $C$. pseudotuberculosis de abscesos en ovinos (Mattos, 1962). En los últimos años, se ha observado un incremento de casos con presencia de abscesos en alpacas de la zona de la Raya-Cuzco. Esta enfermedad ha venido ocasionando considerables pérdidas económicas en el país, principalmente debido a la condenación de las carcasas por la formación de abscesos, disminución en la producción de la fibra, disminución en el peso y trastornos reproductivos, dificultando además la exportación de las alpacas; motivos por los cuales se hace necesario controlar y prevenir esta enfermedad (Villena, 1985).

El C. pseudotuberculosis es una bacteria intracelular facultativa, cuyo principal factor de virulencia es una exotoxina, que es una Fosfolipasa $\mathrm{D}$ producida por la membrana celular de la bacteria, la cual es capaz de promover la diseminación bacterial por incremento de la permeabilidad vascular en cobayos y ratones (Hodgson, 1999). La vacunación empleando la exotoxina como antígeno ha demostrado ser de gran utilidad al prevenir la infección inicial de la bacteria en ovinos (Eggleton, 1991).

El propósito del presente trabajo fue elaborar una vacuna basada en la exotoxina Fosfolipasa D obtenida de Corynebacterium pseudotuberculosis y demostrar, mediante vacunación e infección en ratones, la eficacia de la vacuna. Los resultados de este experimento serán útiles para futuros trabajos orientados hacia la búsqueda de lograr la prevención y el control sanitario de la linfadenitis granulomatosa en alpacas.

\section{Extracción del ADN de C. pseudotu- berculosis}

La extracción del ADN se realizó con el kit comercial WIZARD DNA Genomics (Promega, USA).

\section{PCR para la detección de C. pseudotu- berculosis}

El PCR fue realizado con un volumen final de 50 1, el cual contenía 51 de PCR buffer 10X, $5 \quad 1$ de $\mathrm{MgCl} 2$ (25mM), $250 \quad \mathrm{M}$ de cada dNTP, $2 \mathrm{U}$ de Taq polymerase (Promega, USA), $1 \quad \mathrm{M}$ de cada primer y 51 de ADN de C. pseudotuberculosis. La amplificación fue obtenida con un paso de desnaturalización inicial a $94^{\circ} \mathrm{C}$ por 5 minutos, seguida de 30 ciclos de $94^{\circ} \mathrm{C}$ por 1 minuto, 56 ${ }^{\circ} \mathrm{C}$ por 1 minuto y $72{ }^{\circ} \mathrm{C}$ por 2 minutos.

La secuencia de los primers son los usados por Cetinkaya et al. (2002). La especificidad de los primers fue comparada con todas las secuencias conocidas en el Banco de Genes (Cetinkaya et al., 2002). Los productos amplificados fueron detectados con tinción de bromuro de etidio $(0.5 \mathrm{~g} / \mathrm{ml})$ después de la electroforesis a $100 \mathrm{~V}$ por $30 \mathrm{mi}-$ nutos en gel de agarosa al $1.5 \%$. Los productos de PCR con un peso molecular de 815 $\mathrm{pb}$ fueron considerados indicativos de la presencia de C. pseudotuberculosis.

\section{Extracción de proteínas de $C$. pseudo- tuberculosis}

La exotoxina constituye una parte importante de las proteínas a extraerse. Para la extracción de las proteínas se utilizó una cepa de C. pseudotuberculosis aislada de alpaca en el sur del país e identificada por su morfología al cultivo y por PCR. Para la extracción de la proteína, se traspasó varias colonias de C. pseudotuberculosis del medio sólido (agar sangre de ovino), a un frasco que contenía $1 \mathrm{~L}$ de caldo de cultivo (caldo tripticasa soya) y se cultivó a $37^{\circ} \mathrm{C}$ durante 60 horas en movimiento constante. 
Al término de la incubación, el caldo se sometió a refrigeración por 1 día. Posteriormente se realizó la centrifugación a 2,000 g por 10 minutos y se recolectó el sobrenadante. Este fue pasado a través de un filtro de $0.22 \mathrm{~m}$ de diámetro. A $500 \mathrm{ml}$ de caldo filtrado se adicionó $162 \mathrm{~g}$ de sulfato de amonio $(55 \%, 324 \mathrm{~g} / \mathrm{L})$ en agitación constante y en refrigeración con el fin de precipitar la proteína, dejándose reposar toda la noche. Al día siguiente el precipitado fue centrifugado a $14,000 \mathrm{~g}$ por 10 minutos. Todo el precipitado proteico fue dializado y monitoreado con cloruro de bario al $1 \%$. Después se determinó la concentración de proteínas por el método de Bradford obteniéndose la concentración de 0.024 g/ 1(Breadford, 1976). Luego se procedió a concentrar la proteína transfiriéndola a una bolsa de diálisis y colocada sobre polietilenglicol hasta obtener una concentración inicial de 40 g/ratón, la cual tuvo que ser disminuida para evitar efectos tóxicos letales en los ratones. Finalmente se logró determinar que la dosis de 16 g/ratón no ocasionaba daños a los animales.

\section{Test de CAMP}

El Test de CAMP se realizó para demostrar la presencia de la exotoxina en el extracto proteico. El Test de Camp consistió en hacer 2 hoyos de $1 \mathrm{~cm}$ de diámetro sobre una placa de agar sangre de ovino, a $1 \mathrm{~cm}$ de distancia uno del otro. Se sembró una estría de Staphylococcus aureus entre los hoyos y después un hoyo fue llenado con la proteína extraída de C.pseudotuberculosis y el otro hoyo con agua destilada estéril, como control. La placa fue incubada a $37{ }^{\circ} \mathrm{C}$ por $24 \mathrm{~h}$ y después a $4^{\circ} \mathrm{C}$ por 24 horas. La finalidad de la prueba fue demostrar la inhibición de la actividad de la beta-toxina (Fosfolipasa C) de Staphylococcus aureus, provocada por la exotoxina (actividad Fosfolipasa D) de C. pseudotuberculosis presente en el precipitado de la proteína.

\section{Vacunación de los ratones}

El tamaño de muestra calculado fue de 20 animales por grupo experimental. Para la vacunación se designó 2 grupos experimentales de ratones albinos de la cepa Balb C, de $20 \mathrm{~g}$ de peso y en buen estado de salud. Un grupo fue designado como grupo de estudio, que fue vacunado e infectado; y el otro grupo fue designado como grupo control, el cual recibió un placebo y fue infectado con $C$. pseudotuberculosis.

Se preparó la vacuna a partir de la exotoxina presente en las proteínas extraídas, determinándose la concentración de proteínas mediante el método de Bradford. La vacuna tuvo una concentración final de 16 g/ratón de proteína extraída, donde está presente la exotoxina. La proteína fue precipitada con hidróxido de aluminio al $0.5 \%$ e inactivada con formaldehído al $0.5 \%$, alcanzando un volumen final de 200 1/dosis/ratón. La inoculación de la vacuna y del placebo se realizó por vía subcutánea en la parte ventral y al lado izquierdo de la línea media del abdomen de los ratones. Se aplicó una dosis de refuerzo de la vacuna 15 días después de la primera dosis vacunal.

\section{Desafío}

Se preparó una suspensión de $C$. pseudotuberculosis de $10^{4}$ UFC por dosis por ratón, mediante el método de Mc Farland. (Sam et al., 1994). Posteriormente se realizó la siembra en placa de agar sangre de ovino para confirmar la dosis mediante el conteo de las colonias de C. pseudotuberculosis. La infección experimental se realizó después de 15 días del refuerzo de la vacuna por vía intraperitoneal. Se realizó la necropsia de todos los animales a los 46 días de la infección. Se tomaron muestras de abscesos de los diferentes órganos afectados y se procedió a realizar el PCR y el aislamiento por cultivo.

\section{Análisis de los resultados}

Para el análisis de datos se utilizó el paquete estadístico SPSS. La supervivencia y el tiempo de aparición de lesiones se caracterizó empleando la curva de Kaplan Meyer y para las diferencias entre curvas y 


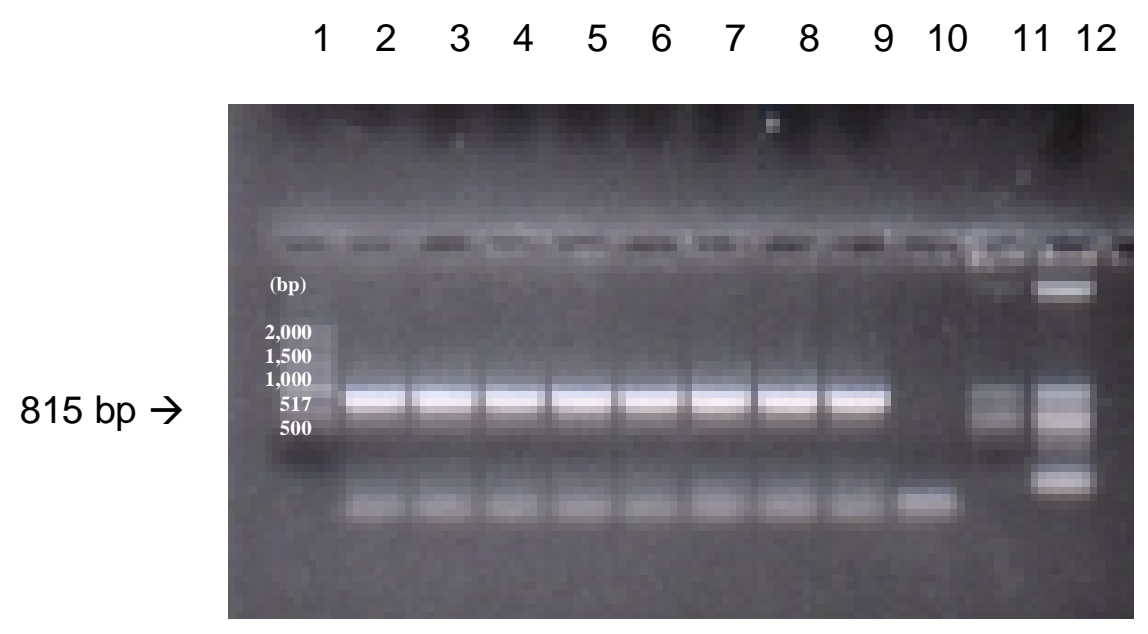

Figura 1. PCR de Corynebacterium pseudotuberculosis. (1) Marcador de peso molecular, (2) $\mathrm{C}+$, (3-9) PCR, (10) C-, (11-12) Extracción de ADN

el ajuste de variables contundentes se emplearon las regresiones del peligro proporcional de Cox.

\section{Resultados}

La cepa aislada de alpaca desarrolló colonias pequeñas, de apariencia translúcida, de color blanco mate y de consistencia desmenuzable; además se observó hemólisis ligera, las cuales son características típicas de C. pseudotuberculosis.

Al realizar el Test de CAMP se observó inhibición de la actividad de la beta-toxina (Fosfolipasa C) de Staphylococcus aureus debido a la acción de la exotoxina (Fosfolipasa D) de Corynebacterium pseudotuberculosis.

En el conteo en la placa de agar sangre ovino de las bacterias viables, se confirmó la dosis de $10^{4}$ UFC inoculada a cada ratón en el desafío.

En la prueba de PCR se observó bandas de DNA de un tamaño de 815 bp, confirmando la presencia de C. pseudotuberculosis (Fig. 1).
En el análisis de supervivencia empleando la curva de Kaplan Meyer se observa que los animales vacunados se encuentran más protegidos, toda vez que el $60 \%$ de ellos no presentaron muestras de infección con C. pseudotuberculosis al día 46, a diferencia del grupo control donde el $95 \%$ de los animales llegaron a infectarse.

Cuando se evalúa la condición no vacunado como factor de riesgo se observa que los animales no vacunados presentan 1.65 veces más probabilidad de que se infecten que aquellos que son vacunados. Sin embargo, cuando se analiza los intervalos de confianza, se observa que éstos incluyen al valor 1 por lo que no se puede descartar que éstos tengan la misma proporción de infección que los no vacunados. Por tanto, las diferencias observadas entre los grupos (control y vacunado) no son significativas.

Todos los animales infectados del grupo vacunado mostraron una infección leve con abscesos localizados en la zona de inoculación y en número de dos como máximo, a diferencia de los animales infectados del grupo control que mostraron múltiples abscesos en riñón, hígado y a nivel subcutáneo, y fueron abscesos de mayor tamaño (figs. 2 y 3 ). Un 
Cuadro 1. Número de lesiones en ratones infectados después de la exposición experimental a Corynebacterium pseudotuberculosis

\begin{tabular}{|c|c|c|c|c|}
\hline \multirow{2}{*}{ Grupo } & \multicolumn{3}{|c|}{ Animales } & \multirow{2}{*}{$\begin{array}{c}\text { Promedio de } \\
\text { lesiones por } \\
\text { animal infectado }\end{array}$} \\
\hline & $\begin{array}{l}\text { Utilizados } \\
\text { (n) }\end{array}$ & $\begin{array}{l}\text { Infectados } \\
\text { (n) }\end{array}$ & $\begin{array}{c}\text { Infectados } \\
(\%)\end{array}$ & \\
\hline Vacunado & 20 & 8 & 40 & 1.5 \\
\hline Control & 20 & 19 & 95 & 6.5 \\
\hline
\end{tabular}

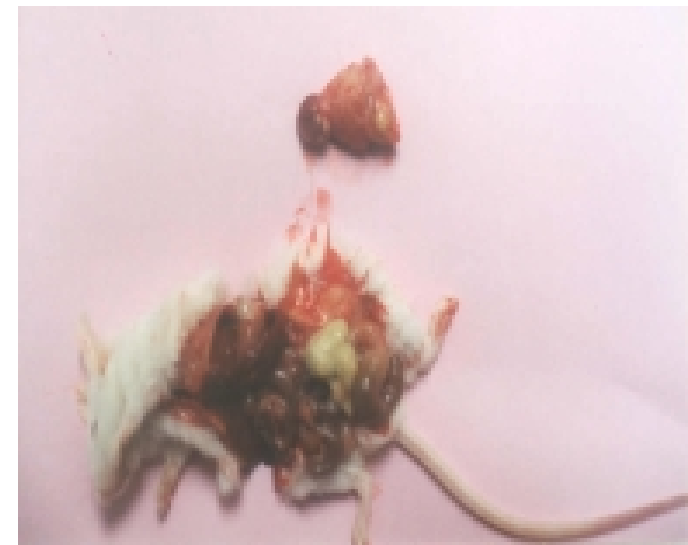

Figura 2. Ratón no vacunado con absceso subcutáneo

hallazgo importante fue la reducción de un promedio de 6.5 lesiones en controles infectados a 1.5 en animales vacunados infectados como se muestra en el Cuadro 1.

\section{Discusión}

La capacidad protectiva de la vacuna elaborada a base de exotoxina de $C$. pseudotuberculosis se demuestra por la menor incidencia de animales susceptibles a la infección generalizada en el grupo vacunado $(40 \%)$ en relación con los animales no vacunados que desarrollaron abscesos (95\%). Sin embargo, cuando se analiza los intervalos de confianza, se observa que no hay diferencias significativas entre los grupos control y

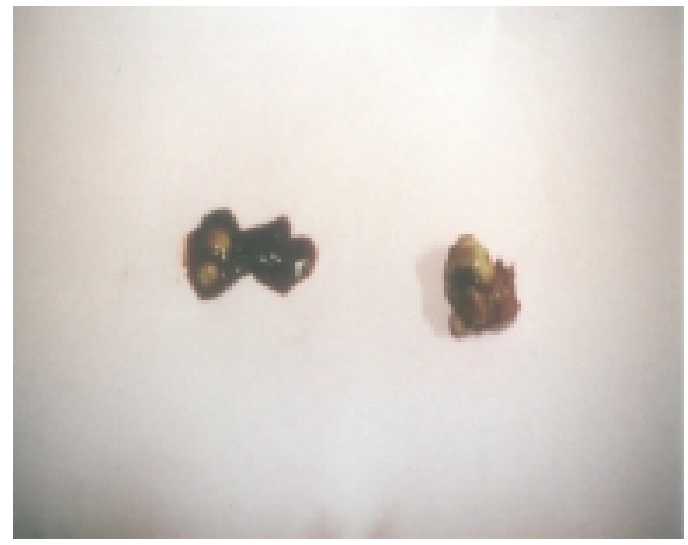

Figura 3. Múltiples abscesos en hígado de ratón no vacunado

vacunados. Es probable que si el tamaño de la muestra hubiera sido más grande, se podría esperar diferencias entre grupos.

Los tejidos y órganos más afectados después de una infección natural en alpacas son los abscesos a nivel subcutáneo, órgano reproductor, riñones e hígado (Villena, 1985). Esos hallazgos son similares a lo observado en el presente estudio, en donde la presentación de abscesos purulentos en los ratones infectados experimentalmente ocurrió con mayor frecuencia en los tejidos y órganos. Por otro lado, no se observó abscesos en los pulmones ni en los nódulos linfáticos superficiales como sucede en ovinos y caprinos.

El C. pseudotubeculosis produce una exotoxina con actividad de Fosfolipasa 
D (PLD), cuya contribución como factor de virulencia puede ser debida en parte, a que facilita la invasión bacteriana incrementando la permeabilidad vascular. La PLD ataca la esfingomielina de la membrana de los eritrocitos y de las células vasculares endoteliales, dividiéndola en fosfato de ceramida y colina (Jolly, 1965b). La colina libre induce cambios estructurales en la superficie celular y en los constituyentes intercelulares, facilitando la permeabilidad.

En un estudio de investigación en ratones realizado por Batey (1986) se demostró que la máxima actividad letal de $C$. pseudotuberculosis está asociada con la actividad dermonecrótica e inhibitoria de la beta-hemólisis. Este efecto dermonecrótico de la exotoxina fue observado en los ratones vacunados del presente estudio en donde la inoculación subcutánea de $40 \mathrm{~g}$ de proteína (incluído exotoxina) indujo la muerte a las 24 horas, con necrosis severa en la zona de inoculación observada en la necropsia. En ese sentido, se procedió a disminuir la dosis vacunal hasta no observar los efectos letales mencionados. Se determinó finalmente, que la dosis $16 \mathrm{~g}$ de proteína por ratón no producía efectos letales. Una de las posibles causas por la cual la vacuna haya podido inducir necrosis en los ratones puede haber sido por la exotoxina presente en la vacuna, la cual a pesar de haber sido inactivada con formaldehído, haya quedado parte de la exotoxina activa, lo cual trae efectos tóxicos (Eggleton, 1991).

Por otro lado, en estudios de investigación realizados por Hodgson et al. (1992), el gen que codifica la exotoxina de $C$. pseudotuberculosis fue eliminado por mutagénesis del sitio específico, creando así una cepa denominada PLD-negativa. Esta cepa no indujo la enfermedad experimental en ovinos, aún a doble dosis infectiva, comparada con la cepa de campo. Esto sugiere que la PLD es uno de los mayores factores de virulencia.

Cameron y Minaar (1969) han sugerido que el principal antígeno inmunizante está asociado con la superficie lipídica de la pared celular. Posteriormente, se deja abierta la posibilidad de que la protección puede depender de una compleja configuración de antígenos, los cuales incluyen a la toxina (Cameron y Purdom, 1971). Esto coincide con lo mencionado por Burrell (1978), quien sugirió un efecto protectivo de antitoxinas aunque otros antígenos puedan también estar involucrados. No todos los tipos de moléculas tienen la misma capacidad inmunogénica. Las proteínas son las más inmunógenas, seguida de carbohidratos y luego de lípidos. Por tal motivo y a diferencia con lo mencionado por Cameron y Minaar (1969), es posible que la exotoxina, por ser una molécula proteica, tenga una ventaja sobre los lípidos de pared celular, como un buen estimulador de la respuesta inmune. Por otro lado, frente a la sugerencia de Burell (1978) y para demostrar qué componente del extracto proteico es el principal inmunógeno sería conveniente realizar un estudio experimental con vacunas preparadas con las proteínas extraídas de $C$. pseudotuberculosis y purificarlas para identificar el o los principales antígenos inmunizantes.

La consecuencia de una infección primaria es el establecimiento de lesiones crónicas de la enfermedad. La reducción de animales infectados y de lesiones en animales infectados pudo deberse a la presencia de anticuerpos circulantes (antitoxina) en el momento de exposición con C. pseudotuberculosis. Esto permitiría la neutralización de la exotoxina secretada, inhibiendo la permeabilidad vascular inducida por la exotoxina y reduciendo la habilidad de la bacteria para invadir ganglios linfáticos locales, hipótesis que sería necesaria demostrar mediante futuros trabajos de investigación.

La presencia de abscesos pequeños y localizados en el grupo vacunado, a diferencia de los animales del grupo control quienes mostraron una infección generalizada, indicaría que la proteína que contiene la exotoxina de C. pseudotuberculosis, aplicada como inmunizante, ha logrado disminuir 
el progreso de la enfermedad en los animales que han recibido la vacuna. Esto tiene importancia económica, ya que el animal, al tener menos abscesos, reduce la probabilidad de rechazo, decomiso de órganos, carcasa y depreciación del producto en el camal. Por otro lado, la reducción del número de abscesos en animales vacunados también ofrece una gran reducción como fuente de infección para otros animales, lo cual es crucial para el control de la enfermedad.

La protección otorgada por la vacuna estuvo orientada a neutralizar la exotoxina Fosfolipasa D y disminuir sus efectos tóxicos, los cuales se han hecho evidentes con la reducción en número y tamaño de los abscesos encontrados en los animales vacunados. Resultados similares han sido reportados con una vacuna comercial, elaborado en Australia, en donde se obtuvo un considerable efecto protectivo medido con la reducción de la prevalencia y el número de lesiones tanto en ovejas como en cabras (Jolly, 1965a). En este sentido, la vacuna elaborada en el presente estudio no impidió la infección, pero si la diseminación de C. pseudotuberculosis en ratones. Es importante seguir ensayando vacunas contra la enfermedad por C. pseudotuberculosis.

\section{Literatura Citada}

1. Batey, R.G. 1986. Pathogenesis of caseous lymphadenitis in sheep and goats. Aust. Vet. J. 63: 269-272.

2. Bradford, M.M. 1976. A rapid and sensitive method for the quantitation of microgram quantities of protein utilizing the principle of protein-dye binding. Anal. Biochem. 72: 248-254.

3. Braga, L.W. 1993. Aislamiento de Corynebacterium pseudotuberculosis en alpacas y llamas adultas. Rev. Inv. Pec. IVITA 6:128-131.

4. Burrell, D.H. 1978. Experimental induction of caseous lymphadenitis in sheep by intralymphatic inoculation of Corynebacterium ovis. Res. Vet. Sci. 24: 269-276.
5. Cameron, C.M; J.L. Minaar. 1969. Immunization of mice against Corynebacterium pseudotuberculosis infection. J. Vet. Res. 36:207-210.

6. Cameron, C.M.; M.R. Purdom. 1971. Immunological and chemical characteristics of Corynebacterium pseudotuberculosis cell walls and protoplasm. J. Vet. Res. 38: 83-92.

7. Cetinkaya, B.; M. Karahan; E. Atil; R. Kalin; T. De Baere; M. Vaneechoutte. 2002. Identification of Corynebacterium pseudotuberculosis isolates from sheep and goats by PCR. Vet. Microb. 88: 75-83.

8. Eggleton, D.G 1991. Immunization against ovine caseus lymphadenitis: comparasion of Corynebacterium pseudotuberculosis vaccines with and without bacterial cells. Aust. Vet. J. 68: 317-319.

9. Hodgson, A.L.; J. Krywult; L.A. Corner; J.S. Rothel; A.J. Radford. 1992. Rational attenuation of Corynebacterium pseudotuberculosis: Potential chessy vaccine and live delivery vehicle. Infect. Imm. 60: 2900-2905.

10. Hodgson, A. 1999. Efficacy of an ovine caseus lymphadenitis vaccine formulated using a genetically inactive form of the Corynebacterium pseudotuberculosis phospholipase D. Vaccine 17: 802-808.

11. Jolly, R.D. 1965a. Experimental infection on convalescent mice with Corynebacterium ovis. N. Z. Vet. J. 13: 148-153.

12. Jolly, R.D. 1965b. The pathogenesis of experimental Corynebacterium ovis infection in mice. N.Z. Vet. J. 13: 141-147.

13. Mattos, R. 1962. Encuesta en el frigorífico Nacional del Callao. Tesis Bachillerato. Fac. Medicina Veterinaria, Univ. Nacional Mayor de San Marcos, Lima. 30 p.

14. Sam, R.; A. Manchego; N. Sandoval, 1994. Guía de Prácticas de Microbiología e Inmunología Veterinarias. Capítulo: Inmunología. Sección de Microbiología. Facultad de Medicina Veterinaria, Univ. Nacional Mayor de San Marcos.

12. Villena, S.C. 1985. Abscesos en alpacas: aspectos microbiológicos. Tesis Bachillerato. Fac. Medicina Veterinaria, Univ. Nacional Mayor de San Marcos, Lima. 18 p. 